\title{
Carbon Nanotubes from Carbon Dioxide
}

\author{
N B Singh * \\ RTDC, Sharda University, Greater Noida, India
}

Received: May 9, 2018; Accepted: May 17, 2018; Published: May 18, 2018

*Corresponding author: N B Singh, RTDC, Sharda University, Greater Noida, India,E-mail: nbsingh43@gmal.com

\section{Abstract}

Green house gas emission particularly emission of $\mathrm{CO}_{2}$ is a major issue in global warming. Numbers of methods are known to convert $\mathrm{CO}_{2}$ into useful product. However, recently conversion of $\mathrm{CO}_{2}$ into CNT is reported. The information is given in this short article.
\end{abstract}

\section{Introduction}

Global warming and global climate changes are due to anthropogenic activities throughout the world [1]. Emissions of greenhouse gases particularly $\mathrm{CO}_{2}$ gas are responsible for greenhouse effect [2]. $\mathrm{CO}_{2}$ emissions by different sectors are given in

Figure 1 [3]. Surface temperature is increasing continuously. Therefore, there is an urgent need to develop technologies that will reduce $\mathrm{CO}_{2}$ emissions.

The easiest way to reduce $\mathrm{CO}_{2}$ concentrations is to reduce $\mathrm{CO}_{2}$ emissions through cleaner and more environmentally friendly industrial processes. However, it is not possible in near future. However, there are many ways to reduce $\mathrm{CO}_{2}$ by converting into number of useful products (Figure 2).

One of the most important nanomaterials is carbon Nanotubes, which can be made from $\mathrm{CO}_{2}$. There are two types of carbon Nanotubes (Single and double walled carbon nanotubes) (Figure 3). Carbon Nanotubes (CNTs) have been extensively studied due to their unique mechanical, electronic, and thermal properties

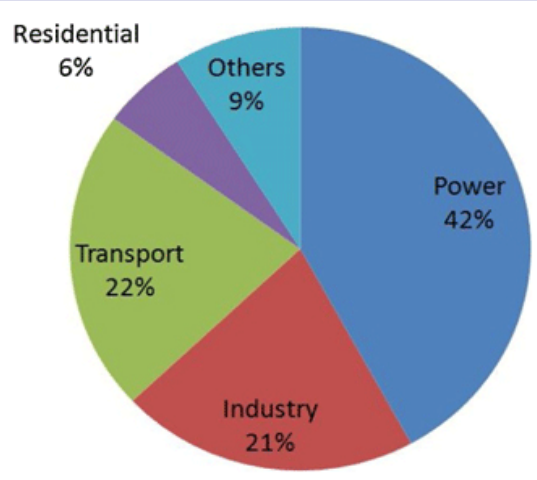

Figure 1: $\mathrm{CO}_{2}$ emissions in 2011

\section{Minimisation of $\mathrm{CO}_{2}$ and its utlization}

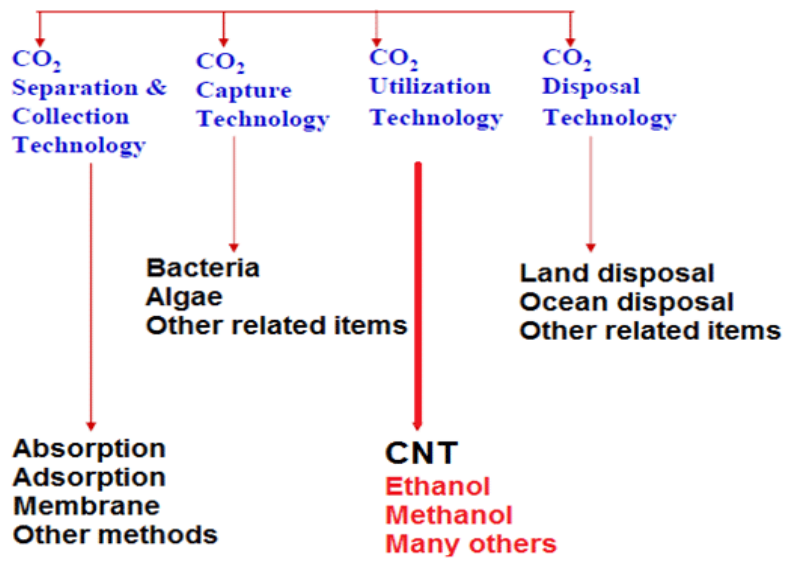

Figure 2: Utilization of $\mathrm{CO}_{2}$

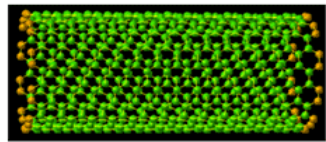

SWCNT

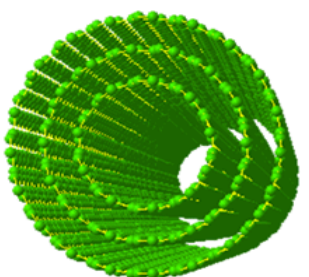

MWCNT
Figure 3: Carbon Nanotubes

There are number of methods for the synthesis of carbon Nanotubes but the most exciting and new is that by $\mathrm{CO}_{2}$ [3]. Numerous $\mathrm{CO}_{2}$ transformation strategies have been proposed to produce CNTs, porous carbon, and graphene using supercritical $\mathrm{CO}_{2}$ or dry ice $[4,5,6]$.

$\mathrm{Li}_{2} \mathrm{CO}_{3}$ with trace concentrations of $\mathrm{Ni}, \mathrm{Cu}$, Fe or Co dissolve $\mathrm{CO}_{2}$ to produce CNTs. Figure 4 shows a two chamber where electrolysis and $\mathrm{CO}_{2}$ dissolution occurs $[7,8]$.

CNTs production by electrolysis in lithium carbonate occurs with the production of oxygen and lithium oxide:

$$
\mathrm{Li}_{2} \mathrm{CO}_{3} \text { (liquid) } ® \mathrm{C}(\mathrm{CNT})+\mathrm{Li}_{2} \mathrm{O} \text { (dissolved) }+\mathrm{O}_{2} \text { (gas) (1) }
$$

$\mathrm{Li}_{2} \mathrm{CO}_{3}$ consumed in Eq.1 is continuously compensated by 
Eq.2.

$\mathrm{Li}_{2} \mathrm{O}$ (dissolved) $+\mathrm{CO}_{2}$ (gas) ${ }^{\circledR} \mathrm{Li}_{2} \mathrm{CO}_{3}$ (liquid) (2)

Net reaction (combining Eqs (1) and (2)):

$\mathrm{CO}_{2}$ (gas) ${ }^{\circledR} \mathrm{C}(\mathrm{CNT})+\mathrm{O}_{2}$ (gas)
Thus from the above reactions $\mathrm{CO}_{2}$ produced is continuously being consumed to give CNT. This is entirely new and novel process for converting $\mathrm{CO}_{2}$ into CNT. If this process is commercialized, there will be a breakthrough in global warming.

CNT synthesized using $\mathrm{CO}_{2}$ is shown in Figure $5[7,8]$.

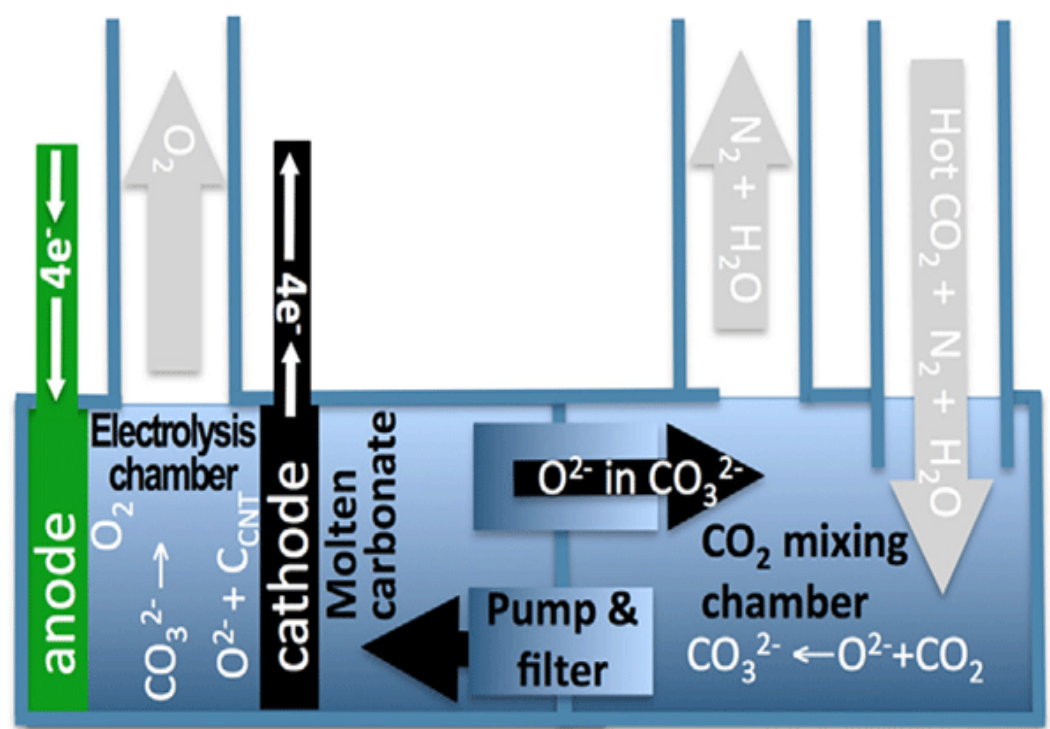

Figure 4: $\mathrm{CO}_{2}$ to $\mathrm{CNT}$ transformation
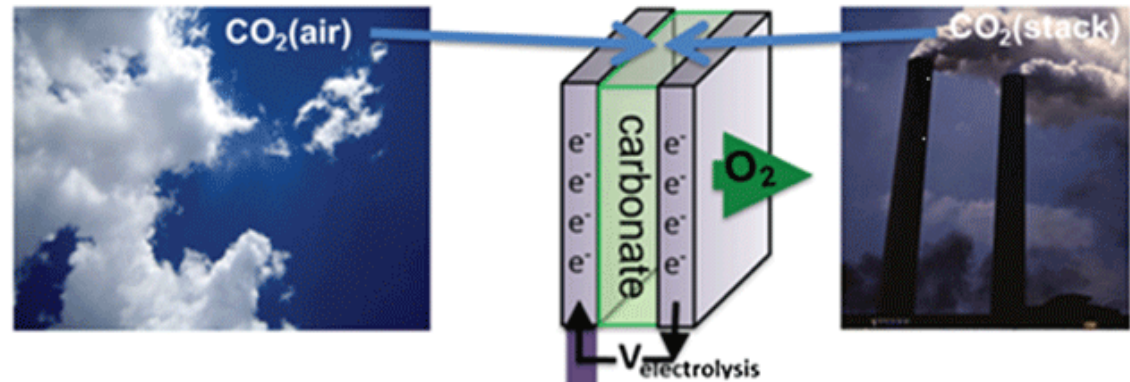

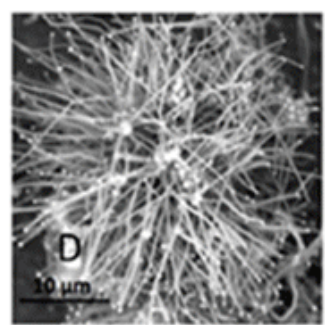

bright Ni nucleation sites

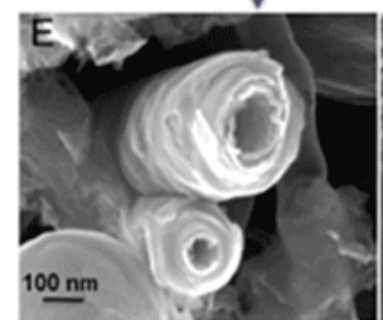

MWCNT

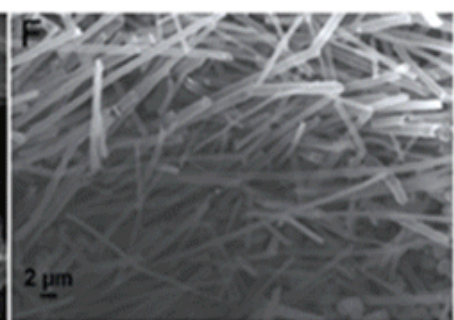

CNTS

Figure 4: Synthesis of carbon nanotubes from $\mathrm{CO}_{2}$ in molten lithium carbonate. 


\section{References}

1. Dhillon R S , George von Wuehlisch. Mitigation of global warming through renewable biomass. Biomass and Bioenergy 2013;48:7589.

2. Jiawen Ren, Marcus Johnson, Richa Singhal, Stuart Licht Transformation of the greenhouse gas $\mathrm{CO} 2$ by molten electrolysis into a wide controlled selection of carbon Nanotubes. Journal of $\mathrm{CO} 2$ Utilization. 2017;18:335-344.

3. Abass A Olajire. Recent progress on the nanoparticles-assisted greenhouse carbon dioxide conversion processes. Journal of $\mathrm{CO}_{2}$ Utilization. 2018;24:522-547.

4. Motiei M, Hacohen Y R, Calderon-Moreno J, Gedanken A. Preparing carbon nanotubes and nested fullerenes from supercritical $\mathrm{CO} 2$ by a chemical reaction. J. Am. Chem. Soc. 2001;123(35):8624-8625. doiI: $10.1021 /$ ja015859a
5. Wei L Z, Chen Q W, Kong X K. Lithium storage properties of porous carbon formed through the reaction of supercritical carbon dioxide with alkali metals. J. Am. Ceram. Soc. 2011;94 (9):3078-3083.

6. Chakrabarti A, Lu J, Skrabutenas J C, Xu T, Xiao Z L, Maguire J A, et al. Conversion of carbon dioxide to few-layer grapheme. J. Mater. Chem. 2011;21(26):9491-9493.

7. Stuart Licht. Co-production of cement and carbon nanotubes with a carbon negative footprint. Journal of CO2 Utilization. 2017;18:378389.

8. Stuart Licht, Anna Douglas, Jiawen Ren, Rachel Carter, Matthew Lefler, Cary L. Pint. Carbon Nanotubes Produced from Ambient Carbon Dioxide for Environmentally Sustainable Lithium-Ion and Sodium-Ion Battery Anodes, ACS Cent. Sci. 2016;2:162-168. doi: 10.1021/acscentsci.5b00400 